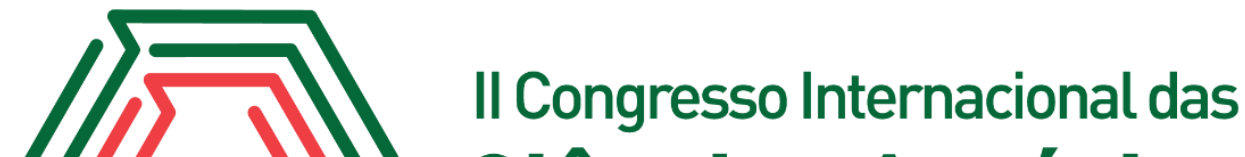 Ciências Agrárias COINTER - PDVAgro 2017
}

\section{TIPOS DE CONTROLE ALTERNATIVO DE PRAGAS E DOENÇAS NOS CULTIVOS ORGÂNICOS NA CIDADE DE ARAGUATINS-TOCANTINS, BRASIL}

\author{
Apresentação: Pôster \\ Rayane Reis Sousa ${ }^{1}$; Samara Lorranny de Souza Garcia²; Ademar do Carmo Junior ${ }^{3}$; \\ Luciana Pinto Fernandes ${ }^{4}$
}

\section{Introdução}

No Brasil, atualmente, há 15 mil agricultores atuando com agricultura orgânica numa área estimada de 800 mil hectares (MAPA, 2008). O Instituto de Desenvolvimento Rural do Tocantins (Ruraltins) tem como princípio contribuir de forma participativa para o desenvolvimento rural sustentável. A Chamada Pública em Agroecologia da Sead visa trabalhar o desenvolvimento social, econômico e ambiental das famílias, bem como consolidar práticas produtivas da agroecologia existentes, focadas na produção saudável de alimentos, livres de agrotóxicos.

Conforme Ricardo Loff, técnico responsável pelo atendimento aos agricultores do povoado Jairnópolis, ou povoado Cabanas, como é conhecido, distante $40 \mathrm{~km}$ do município de Araguatins, no local residem cerca de 15 famílias, destas, apenas oito aderiam as práticas agroecológicas, preconizadas na Chamada Pública. "Os produtores do povoado já trabalham com as metodologias agroecológicas de forma tradicional, no entanto, faltam-lhes conhecimentos de algumas tecnologias que potencializam a produção, como por exemplo, a correção de solo.

O principal objetivo com este estudo foi identificar quais os tipos, e as formas de aplicações, dos controles alternativos realizados por agricultores orgânicos da Cidade de Araguatins. A amostra englobou 20 agricultores orgânicos que fazem parte de associações de produtores rurais de alguns povoados e assentamentos, de Araguatins-TO.

\section{Fundamentação Teórica}

\footnotetext{
${ }^{1}$ Bacharelado em Agronomia, IFTO-Campus Araguatins, E-mail: rayanereis_sousa@hotmail.com

2 Bacharelado em Agronomia, IFTO- Campus Araguatins, E-mail: slorranny@hotmail.com

${ }^{3}$ Graduado em Zootecnia, PUC- Goiás, E-mail: acjconsultoriazootecnica@gmail.com

${ }^{4}$ Mestre em Educação, IFTO- Campus Araguatins, E-mail: luciana@ifto.edu.br
} 
O Brasil ainda é um país agrícola e além disso é o maior consumidor de pesticidas na América Latina, utilizando em torno $1,5 \mathrm{~kg}$ de pesticidas por hectare cultivado. Porém quando o cultivo é de horticultura o consumo médio anual chega a $10 \mathrm{~kg}$ por hectare (ROEL et al., 2000).

O monitoramento sistemático de doenças e pragas é que definirá a necessidade ou não de intervenção, que somente poderá ser feita com produtos permitidos pela legislação em vigor e aceitos pelas certificadoras. Alguns procedimentos alternativos, como a biofumigação e a solarização, estão em desenvolvimento (GHINI \& BETTIOL, 2000; SOUZA \& RESENDE, 2003; PATRÍCIO, 2007).

Dentre vários fatores que implicam na dinâmica de produção, destacam-se o controle de pragas e doenças, que podem ser manejadas de diversas formas. $\mathrm{O}$ manejo integrado de pragas, por exemplo, incide num sistema de manejo no qual se empregam todas as técnicas e métodos apropriados da forma mais compatível possível, mantendo a população da praga a níveis baixos de tal forma que não provoquem prejuízos econômicos (NAIKA et al., 2006).

\section{Metodologia}

O estudo foi realizado no município de Araguatins- TO, latitude: 05 39' 04" S, longitude: 48 $07^{\circ}$ 28" W, altitude: 103m. A amostra englobou 20 agricultores orgânicos que fazem parte da área rural de Araguatins-TO. Entrevistas semiestruturadas foram aplicadas aos responsáveis pela produção orgânica de cada propriedade com 17 questões.

No questionário aplicado constavam informações sobre o entrevistado, sobre a planta e/ou o (s) controle (s) alternativo (s) utilizado (s), como a forma de preparo, a frequência de aplicação, a dosagem e eficiência do princípio ativo, etc.

Em média foram realizadas três entrevistas por agricultor, registro fotográfico das etapas de preparação do controle alternativo, bem como dos principais danos causados por pragas e doenças nos cultivos das propriedades visitadas.

Todos os entrevistados são produtores de alimento orgânico, além da atenção do Estado, também são beneficiados pelo governo federal e conseguiram financiamento por meio do Pronaf Eco, um programa de crédito destinado para investimentos em técnicas agroecológicas. E o estudo foi desenvolvido de janeiro a dezembro de 2016. 


\section{Resultados e Discussões}

O principal problema relatado por todos os agricultores entrevistados é o de combater as pragas. Pois, na maioria das propriedades rurais o cultivo predominante antes era a fumicultura, na qual eram usadas quantidades excessivas de agrotóxicos para o combate de insetos.

Observa-se, um entendimento errôneo de alguns agricultores na aplicação dos princípios ativos para controlar certas pragas e/ou doenças de plantas, a exemplo de calda bordalesa que tem ação fungicida, mas é aplicada como inseticida.

O preparo de todos os extratos e caldas utilizados no controle alternativo de pragas e doenças dos cultivos orgânicos visitados é produzido pelos próprios produtores rurais, em geral com matéria prima proveniente das áreas de cultivos. Eles também realizam rotação de culturas e uso de métodos alternativos de controle de pragas (Tabela 1).

Uma exceção é o preparo do biofertilizante (que também tem aplicação inseticida). Esse biofertilizante é ainda pouco abordado na literatura, entretanto Kupper et al. (2006) relataram sobre o uso de biofertilizantes produzidos a partir da fermentação anaeróbica e aeróbica de esterco bovino.

O leite de vaca cru é utilizado in natura misturado a água na proporção de $10 \%$ para controle de oídio, principalmente em mudas de diferentes culturas: tomate, cebola, alho, etc. De acordo com Bettiol (2000), o leite cru apresenta mecanismos diferenciados tendo uma ação direta sobre os fungos por conter propriedade germicida e também contêm vários aminoácidos na sua composição, que induzem resistências as plantas.

O óleo de Neem é um composto natural extraído a frio das sementes da árvore do Neem (Azadirachta Indica). É um inseticida totalmente natural, pode ser usado em tratamentos preventivos ou em tratamentos de controle, (segundo os produtores) devendo-se fazer a aplicação à tarde, pois é um produto foto sensível, quanto menos luminosidade solar estiver, maior será sua ação.

O uso da urina de vaca sobre os cultivos tem efeito fertilizante, fortificante (estimulante de crescimento) e também o efeito repelente devido ao cheiro forte. Misturada à água na proporção de $10 \%$, pode ser pulverizada de imediato ou ser armazenada em recipientes fechados (geralmente plásticos não transparentes), o que, segundo os entrevistados, aumenta sua eficácia. 
Tabela 1: Tipos de controle alternativos utilizados nos cultivos orgânicos de Araguatins-TO, levantamento realizado de janeiro a dezembro de 2016. Fonte: Sousa,2017.

\begin{tabular}{ccc}
\hline Controle Alternativo & Principal Aplicação & Frequência de Aplicação \\
\hline Soro de leite & Oídio & Mensal \\
Urina de vaca & Mosca-branca & Mensal \\
Óleo de neem & Repelente & Semanal \\
Calda sulfocálcica & Inseticidas & Semestral \\
Calda bordalesa & Fungicidas: (Diversas) & Semestral \\
Sabão de coco & Diversas & Mensal \\
E extratos vegetais & Diversos insetos-pragas & Semanal \\
\hline
\end{tabular}

Os extratos vegetais são produzidos a partir de folhas, frutos e sementes coletados localmente. As partes vegetais são cortadas no liquidificador industrial e, posteriormente, misturadas com água ou álcool e armazenadas em recipientes fechados para fermentação, ou são aplicadas diretamente sobre as plantas afetadas.

Os extratos vegetais são maioria entre os controles alternativos empregados. Seis espécies botânicas são utilizadas para fins distintos: repelir insetos fitofágos, e também na forma de extratos, quando parte da planta é coletada para a preparação em forma aquosa ou alcoólica. O neem (Azadirachta indica A. Juss) e o alho (Allium sativum) são os mais citados (Tabela 2).

Tabela 2: Plantas usadas como repelentes, ou na forma de extratos para o controle alternativo de pragas dos cultivos orgânicos de Araguatins, TO, levantamento de janeiro de 2016 a dezembro de 2016. Fonte: Sousa,2017.

\begin{tabular}{cccccc}
\hline Nome popular & $\begin{array}{c}\text { Nome } \\
\text { científico }\end{array}$ & Parte utilizada & $\begin{array}{c}\text { Forma de } \\
\text { utilização }\end{array}$ & \% de citação & $\begin{array}{c}\text { Principal } \\
\text { aplicação }\end{array}$ \\
\hline Pimenta & Capsilum sp. & Fruto & Extrato & $30 \%$ & Lesmas \\
Cebola & Allium cepa & Bulbos & Extrato & $30 \%$ & Repelência \\
Neem & $\begin{array}{c}\text { Azadirachta } \\
\text { indica }\end{array}$ & Folhas & Fruto & $50 \%$ & $\begin{array}{c}\text { Inseticida } \\
\text { (quaisquer } \\
\text { pragas) }\end{array}$ \\
Laranja & Citrus sinensis & Casca & Extrato cru & $15 \%$ & Pulgões \\
Alho & Allium sativum & Bulbos & Extrato & $45 \%$ & Larva-minadora \\
Mandioca & $\begin{array}{c}\text { Manihot } \\
\text { esculenta }\end{array}$ & $\begin{array}{c}\text { Manipueira } \\
\text { (subproduto) }\end{array}$ & Pó & $10 \%$ & Nematicida \\
\hline
\end{tabular}


De todas as pragas citadas pelos agricultores entrevistados, o pulgão foi citado como de difícil controle e prejuízos frequentes nas olerícolas, proporcionando uma redução populacional quando aplicado extrato cru da casca da laranja, com três a quatro aplicações semanais.

Convém observar que a matéria prima empregada nas preparações dos extratos é proveniente de plantas espontâneas ou cultivadas (neem, pimenta, mandioca, alho, cebola). Deste modo, isto reduz a possibilidade de impacto ambiental sobre o ecossistema pela exploração destas espécies vegetais.

\section{Conclusões}

A relação entre o número de aplicações com a incidência de pragas e doenças, não foi avaliada neste estudo. Contudo, foi observado que nas propriedades em que utilizavam repetidas vezes os extratos de plantas houve menores perdas da produção por ataques de pragas.

De forma geral, os extratos utilizados no controle alternativo das pragas e doenças eram realizados sem aferição das dosagens, frequência de aplicação, e identificação do agente causal.

Os vários tipos de controle alternativo apresentados no referido estudo pode ser uma opção viável ao uso de agrotóxicos, porém, há necessidade de mais estudos, principalmente relacionando o tipo de controle com as pragas e doenças particulares, visando auxiliar os agricultores na produção de alimentos livres de agrotóxicos e impactando menos o ambiente.

\section{Referências}

BETTIOL, W. Leite de vaca cru controla doença da abobrinha. A lavoura, Rio de Janeiro, v.35, p. 34-35, dez, 2000.

GHINI R \& BETTIOL W (2000) Proteção de plantas na agricultura sustentável. Cadernos de Ciência \& Tecnologia, 17:61-70.

KUPPER, K.C. et al. Biofertilizer for control of Guignardia citricarpa, the causal agent of citrus black spot. Crop Protection, v.25, p.569-573, 2006. 
MAPA. Ministério da Agricultura, Pecuária e Abastecimento. Atualmente, há 15 mil produtores atuando com agricultura orgânica numa área estimada de 800 mil hectares. 2008. Acesso em 01/01/2017. Disponível: http://www.planetaorganico.com.br/decreto6323. htm.

NAIKA, S.; JEUDE, J.L.; GOFFAU, M.; HILMI, M.; DAM, B. A cultura do tomate: produção, processamento e comercialização. 1. Ed. Prota, 2006. 104 p.

PATRÍCIO FRA (2007). Palestra: Controle de doenças de hortaliças - convencional vs. Alternativo. Biológico, 69:87-90.

ROEL, A.R. et al. Atividade tóxica de extratos orgânicos de Trichilia pallida Swartz (Meliaceae) sobre Spodoptera frugiperda (J.E. SMITH). Anais da Sociedade Entomológica do Brasil, v.29, n.4, p. 799-808, 2000.

SOUZA JL \& RESENDE P (2003) Manual de horticultura orgânica. 2ªed. Viçosa, Aprenda Fácil. $843 p$. 